\begin{tabular}{|c|c|c|c|}
\hline \multirow{3}{*}{$\begin{array}{r}\text { Case Reports in } \\
\text { Gastroenterology }\end{array}$} & Case Rep Gastroenterol 20 & & \multirow[b]{2}{*}{$\begin{array}{l}\text { Karger } \\
\text { Open ăccess }\end{array}$} \\
\hline & $\begin{array}{l}\text { DOI: 10.1159/000454708 } \\
\text { Publisnea oninne: January 6, } 2017\end{array}$ & $\begin{array}{l}\text { (c) } 2016 \text { The Author(s) } \\
\text { Published by S. Karger AG, Basel } \\
\text { www.karger.com/crg }\end{array}$ & \\
\hline & $\begin{array}{l}\text { This article is licensed under th } \\
\text { International License (CC BY-NC } \\
\text { Usage and distribution for comme }\end{array}$ & $\begin{array}{l}\text { nons Attribution-NonCommercial } 4.0 \\
\text { ger.com/Services/OpenAccessLicense) } \\
\text { uires written permission. }\end{array}$ & \\
\hline
\end{tabular}

\title{
An Unusual Case of Rectal and Ileal Carcinoid Tumors
}

\author{
Molham Abdulsamad Naeem Abbas Bhavna Balar \\ Department of Medicine, Division of Gastroenterology, Bronx Lebanon Hospital Center, \\ Bronx, NY, USA
}

\section{Keywords}

Carcinoid tumor $\cdot$ Terminal ileum $\cdot$ Ileoscopy $\cdot$ Ileal and rectal carcinoids

\begin{abstract}
Carcinoid tumor is the most common neuroendocrine tumor affecting the gastrointestinal tract. The coexistence of multifocal carcinoid lesions is a well-established phenomenon. Although intubation of the terminal ileum is not routinely attempted during colonoscopy, it can occasionally reveal the presence of some incidental findings. We present a patient with known rectal carcinoid, who was found to have another carcinoid lesion in the terminal ileum during surveillance colonoscopy. The patient underwent right hemicolectomy, and no chemotherapy was required as the patient was found to have stage 1 carcinoid tumor.
\end{abstract}

(C) 2016 The Author(s)

Published by S. Karger AG, Basel

\section{Introduction}

Intubation of the terminal ileum was not routinely attempted during colonoscopy due to time constraints and sometimes technical difficulties unless there is a suspicion of inflammatory bowel disease. Since the introduction of quality indicators for colonoscopy completion has included the need to document at least 2 landmarks (appendix, ileocecal valve, terminal ileum), intubation of the terminal ileum is being done more frequently. Occasionally, an intubation of the terminal ileum can reveal the presence of some other incidental findings. 
We present a patient with known rectal carcinoid, who was found to have another carcinoid lesion in the terminal ileum during surveillance colonoscopy. It is difficult to say with certainty whether this ileal carcinoid lesion has been present ever since the diagnosis of rectal carcinoid or whether it developed later on. However, during the last surveillance colonoscopy, the terminal ileum was intubated and surprisingly a polypoid lesion was seen in the terminal ileum, the biopsy of which showed a carcinoid tumor. The patient underwent right hemicolectomy, and no chemotherapy was required as the patient was found to have stage 1 carcinoid tumor.

The term carcinoid (carcinoma-like) was historically first introduced by Oberndorfer in 1907 when he described a morphologically distinct intestinal tumor [1].

Gastrointestinal (GI) carcinoid tumors generally refer to neuroendocrine tumors that originate in the digestive tract. They comprise around $70 \%$ of all carcinoid tumors, while the remaining are mainly found in the respiratory tract followed by the kidney and ovary. They occur most commonly in the small intestine (where the ileum is the most common site), followed by the rectum, appendix, colon, and stomach. GI carcinoids are relatively rare tumors although its overall incidence has been rising over time. However, this is probably somewhat related to the increased detection and implementation of screening colonoscopy.

GI carcinoid tumors arise from enterochromaffin cells. These are neuroendocrine cells that play a key role in GI motility by modulating the enteric nervous system via the secretion of the neurotransmitter serotonin.

Histologically, these tumors are subclassified into either well-differentiated or poorly differentiated tumors. This is based on the tumor grade (low, intermediate and high grade), which can be determined by the proliferative activity of the tumor, usually measured by the mitotic rate or the Ki-67 index (nuclear protein necessary for cellular proliferation and correlates with the clinical course of cancer). An index of $<3 \%$ indicates a low-grade, welldifferentiated tumor, while $>20 \%$ indicates a high-grade, poorly differentiated tumor.

Immunohistochemical staining is positive for the neuroendocrine markers that are usually expressed by these tumors including synaptophysin, chromogranin A, neuron-specific enolase, and CD59.

Carcinoid tumors are malignant tumors but relatively slow-growing with an indolent course. Some tumors behave aggressively and present with metastases at the time of diagnosis particularly with small intestinal carcinoids.

Treatment and prognosis depends on the size, stage, grade, resectability and distant metastasis. For localized tumors, surgical resection should be performed if the tumor is resectable. For advanced-stage tumors, control of symptoms of carcinoid syndrome and prudent use of antitumor therapy is essential.

\section{Case Summary}

A 56-year-old woman was evaluated in a gastroenterology clinic for surveillance colonoscopy. About 9 years ago, she had undergone an endoscopic workup for hypochromic microcytic anemia. Upper GI endoscopy revealed congested mucosa in the gastric body. Gastric biopsy revealed Helicobacter pylori bacteria and duodenal biopsy showed no significant pathological changes. She was treated for $H$. pylori and eradication was confirmed. Colonoscopy at that time had revealed an 8-mm polyp in the rectum, the pathology of which showed low-grade carcinoid tumor, with the involvement of margins. She was also noted to have few subcentimeter tubular adenomas. She had surveillance colonoscopies done at appropriate 
intervals and during the last colonoscopy, she was found to have a polypoid lesion in the terminal ileum, the biopsy of which revealed carcinoid tumor grade 1 involving the lamina propria and submucosa with a positive margin. The patient did not have any GI symptoms to suggest carcinoid syndrome. Her laboratory studies suggested mild microcytic anemia with a hemoglobin level of $12.4 \mathrm{~g} / \mathrm{dL}$, and a mean corpuscular volume of 66 . The rest of the laboratory data were all within normal limits. Further workup included small bowel series radiography to exclude any concomitant lesions and CT scan of the abdomen and pelvis to exclude distant metastasis. Both studies were negative for any other GI or distant lesions.

The patient underwent resection of the terminal ileum with right hemicolectomy. The lesion in the ileum measured $1 \times 0.8 \times 0.8 \mathrm{~cm}$. Pathology examination showed a welldifferentiated low-grade carcinoid tumor invading the submucosa (Fig. 1, Fig. 2). Immunohistochemical staining was positive for neuron-specific enolase, which specifies a neuroendocrine differentiation of the tumor (Fig. 3). Surgical margins were free of malignancy. There was no lymphovascular or perineural invasion and 10 out of 10 lymph nodes were negative for tumor. Specific stain for Ki-67 was $<2 \%$ (Fig. 4). The tumor was staged as pT1 pN0. No chemotherapy was required. The patient has been followed and surveillance colonoscopy will be repeated after 1 year.

\section{Discussion}

Malignant tumors of the small bowel are uncommon, accounting for $2 \%$ of all GI cancers, and the major histological subtypes include adenocarcinoma, lymphoma, gastrointestinal stromal tumor and carcinoid tumors [2]. Carcinoid tumor is the most common neuroendocrine tumor affecting the GI tract. Its occurrence rate is about 1 case in 300 autopsies, and without metastasis it has a vague and protean clinical manifestation, accounting for the delay in diagnosis. The rate of metastasis has been reported to be 1 in 30,000. Two-thirds of all carcinoid tumors affecting the GI tract involve the small intestine and the appendix [3].

Clinical manifestations of carcinoid tumors depend on the site of involvement, the presence of the metastasis or the carcinoid syndrome. Midgut carcinoids can present with abdominal pain, intermittent obstruction, and a palpable abdominal mass. Once the tumor has invaded the mesentery, it can lead to a desmoplastic reaction with scarring or a mass with intermittent obstruction of the intestine. Ileal carcinoid has been described to be associated with ischemia, especially if it is associated with mesenteric metastasis [4]. The mechanism of development of intestinal ischemia in the setting of mesenteric metastasis is thought to be due to a severe desmoplastic reaction, though the exact mechanism is not completely understood. Ileal carcinoid can have varied, nonspecific symptoms such as occult or overt GI bleeding, volvulus, intestinal obstruction, or can be discovered as an incidental finding during screening colonoscopy. A recent report by Kara and Dunzendorfer [5] found a $0.1 \%$ incidence of terminal ileum carcinoids detected during screening colonoscopy. Four out of 5 patients underwent ileocecal resection and adjacent lymph node resection and all of them had metastases or a second carcinoid lesion, and these abnormalities were not detected on extensive preoperative workup [5]. A case series of 6 cases of ileal carcinoid were detected through the routine use of ileoscopy during screening colonoscopy over the past 5 years and metastatic disease to the regional lymph nodes was observed if the lesion size was $\geq 1 \mathrm{~cm}$ in size [6].

Carcinoid tumor can also present with metastasis to different organs such as the liver, lungs, and mesentery and to unusual places such as the spleen, testes, thoracic wall or facial 
bones. Carcinoid syndrome can present with facial flushing, palpitation, dyspnea, itching sensation and features of right heart failure due to regurgitation of right-sided valves [7].

A retrospective study of 167 cases of carcinoid involving the jejunum and ileum revealed that only $5 \%$ had carcinoid syndrome, $77 \%$ had transmural involvement and about one-third had liver or mesenteric metastasis [8]. There is a high association between carcinoids of the small intestine and other cancers, with the reported frequency as high as $29 \%$.

Given that small intestinal carcinoids are derived from the midgut and rectal carcinoids are derived from the hindgut, it is common to find multiple small intestinal carcinoids at the time of diagnosis based on genetic clonality and the known clinical multiplicity behavior of these tumors. It is very uncommon for large intestinal carcinoid to have metastasis to the small intestine, and it is rarely reported to have simultaneous carcinoids of the small and large bowel.

We are not sure whether our patient had ileal carcinoid lesion at the time of diagnosis of the rectal carcinoid, as the terminal ileum was not examined during the first colonoscopy. The coexistence of carcinoid tumor at a different place than the original tumor have been described with a variety of tumors such as esophageal adenocarcinoma, gastric adenocarcinoma, colonic neoplasm, lung cancers, and many others. Even 2 primary carcinoid lesions involving 2 organs from 2 different body systems such as gallbladder and ovary have been described [9].

A study by Kundrotas et al. [10] suggested that even though the terminal intubation can be achieved in up to $79 \%$ of the cases, the routine ileoscopy was unrewarding for identifying any pathology, and an attempt of terminal ileal intubation may be conducive for acquiring or improving the endoscopic skills. However, in symptomatic cases such as patients with chronic diarrhea or suspected inflammatory bowel disease, ileoscopy should be attempted. Even though ileoscopy can help firmly document the completeness of colonoscopy, it has a low yield for revealing any pathology (2.7\%) in asymptomatic individuals undergoing screening or surveillance colonoscopy, whereas a higher yield of ileal abnormalities was seen in $18 \%$ of HIV-negative individuals and in $67 \%$ of HIV-positive individuals undergoing colonoscopy for the evaluation of diarrhea [11].

A more recent study by Emami et al. [12] identifies that routine ileoscopy in symptomatic patients is safe, feasible, and should be performed, as normal findings are also beneficial in patients' clinical management.

Based on small bowel involvement in up to $29 \%$ of cases of carcinoid tumor involving the GI tract, its slow progression, difficulty in diagnosis and localization and often incidental finding after bowel resection for obstructive symptoms, it has been suggested to do further workup for ileal carcinoid to exclude multiple or concomitant carcinoid lesions. Suggested investigations include conventional imaging techniques, and if that is unrevealing, capsule endoscopy and balloon-assisted enteroscopy can be attempted, though this is not well established in guidelines yet [13]. Yamaguchi et al. [14] described 1 case of multiple ileal carcinoids diagnosed with the help of balloon-assisted enteroscopy. The patient presented with GI bleeding and anemia and conventional investigations including esophagogastroduodenoscopy, colonoscopy, CT scan of the abdomen and pelvis and double contrast barium enema were inconclusive. 


\section{Conclusion}

Routine ileoscopy in asymptomatic patients can reveal incidental findings. Though it is unrewarding in most asymptomatic patients, it must be attempted in patients with symptoms such as chronic diarrhea and suspected inflammatory bowel disease.

The coexistence of multifocal carcinoid lesions is a well-established phenomenon. Smallbowel carcinoid tumors account for 15-29\% of all GI carcinoid tumors, and account for 17$46 \%$ of all malignant small-bowel tumors [15]. If a carcinoid lesion is found in the colorectal region, we suggest including inspection of terminal ileum during surveillance colonoscopy.

\section{Statement of Ethics}

The authors have no ethical conflicts to disclose.

\section{Disclosure Statement}

All authors have confirmed that the article has not been published elsewhere nor is it currently under consideration for publication elsewhere. All authors have made contributions to the article and have reviewed it before submission and agreed to its publication in this form. All authors declare that there is no conflict of interest regarding the publication of this paper.

\section{References}

1 Kloppel G: Oberndorfer and his successors: from carcinoid to neuroendocrine carcinoma. Endocr Pathol 2007;18:141-144.

2 Mogollon M, Conde R, Segura I, Huertas F, San-Miguel C, Ferron JA, et al: Ileal carcinoid tumor within Crohn's disease. Rev Esp Enferm Dig 2014;106:298-299.

3 American Cancer Society: What are the key statistics about gastrointestinal carcinoid tumors? American Cancer Society. 2015.

http://www.cancer.org/cancer/gastrointestinalcarcinoidtumor/detailedguide/gastrointestinalcarcinoid-tumors-key-statistics.

4 Chapuis P, Weedon D: Ischaemic ileal necrosis and carcinoid tumour. Aust NZ J Surg 1976;46:63-64.

5 Kara FM, Dunzendorfer T: Detection of asymptomatic ileal carcinoid tumors during screening colonoscopy with surgical follow-up. Am J Gastroenterol 2010;105:2511-2512.

6 Yarze JC, Herlihy KJ, Coombes JM, Bauer WM, Fritz HP, D’Agostino JA: Detection of asymptomatic ileal carcinoid tumors during ileal intubation at screening colonoscopy: a case series. Am J Gastroenterol 2009;104:3114-3115.

7 Sakai D, Murakami M, Kawazoe K, Tsutsumi Y: Ileal carcinoid tumor complicating carcinoid heart disease and secondary retroperitoneal fibrosis. Pathol Int 2000;50:404-411. Burke AP, Thomas RM, Elsayed AM, Sobin LH: Carcinoids of the jejunum and ileum: an immunohistochemical and clinicopathologic study of 167 cases. Cancer 1997;79:1086-1093.

-9 Bassi R, Arora R, Bhasin S, Khurana N: An unusual case of synchronous carcinoid of ovary and gall bladder. Case Rep Obstet Gynecol 2013;2013:737016.

10 Kundrotas LW, Clement DJ, Kubik CM, Robinson AB, Wolfe PA: A prospective evaluation of successful terminal ileum intubation during routine colonoscopy. Gastrointest Endosc 1994;40:544-546.

-11 Zwas FR, Bonheim NA, Berken CA, Gray S: Diagnostic yield of routine ileoscopy. Am J Gastroenterol 1995;90:1441-1443.

-12 Emami MH, Behbahan IS, Zade HD, Daneshgar H: New interpretation for diagnostic yield of ileoscopy: a prospective study and a brief review. J Res Med Sci 2009;14:157-163.

13 Matsushita M, Tanaka T, Wakamatsu T, Danbara N, Kawamata S, Ikeda H, et al: Detection of ileal carcinoid tumor needs further investigations for other lesions. Am J Gastroenterol 2010;105:2508. 


\section{Case Reports in \\ Gastroenterology}

\begin{tabular}{l|l}
\hline Case Rep Gastroenterol 2016;10:793-799 \\
\hline DOI: 10.1159/000454708 & $\begin{array}{l}\text { ○ 2016 The Author(s). Published by S. Karger AG, Basel } \\
\text { www.karger.com/crg }\end{array}$ \\
\hline
\end{tabular}

Abdulsamad et al.: An Unusual Case of Rectal and Ileal Carcinoid Tumors

14 Yamaguchi T, Manabe N, Tanaka S, Fukumoto A, Shimamoto M, Nakao M, et al: Multiple carcinoid tumors of the ileum preoperatively diagnosed by enteroscopy with the double-balloon technique. Gastrointest Endosc 2005;62:315-318.

15 Modlin IM, Sandor A: An analysis of 8,305 cases of carcinoid tumors. Cancer 1997;79:813-829.

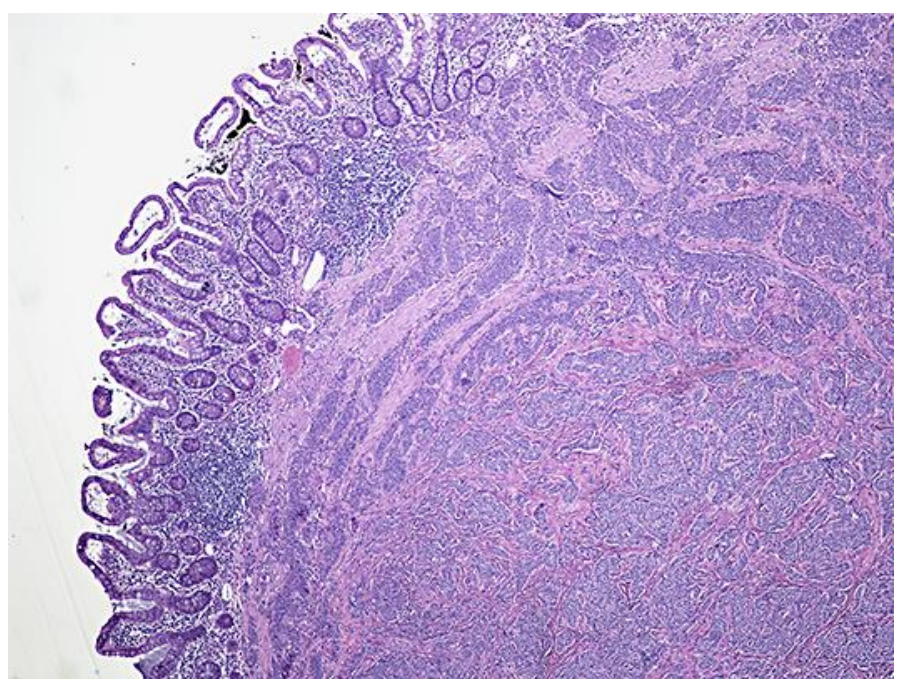

Fig. 1. Well-differentiated neuroendocrine neoplasm of the ileum with predominantly submucosal and deep mucosal involvement by the tumor cells. H\&E stain. $\times 40$ magnification.

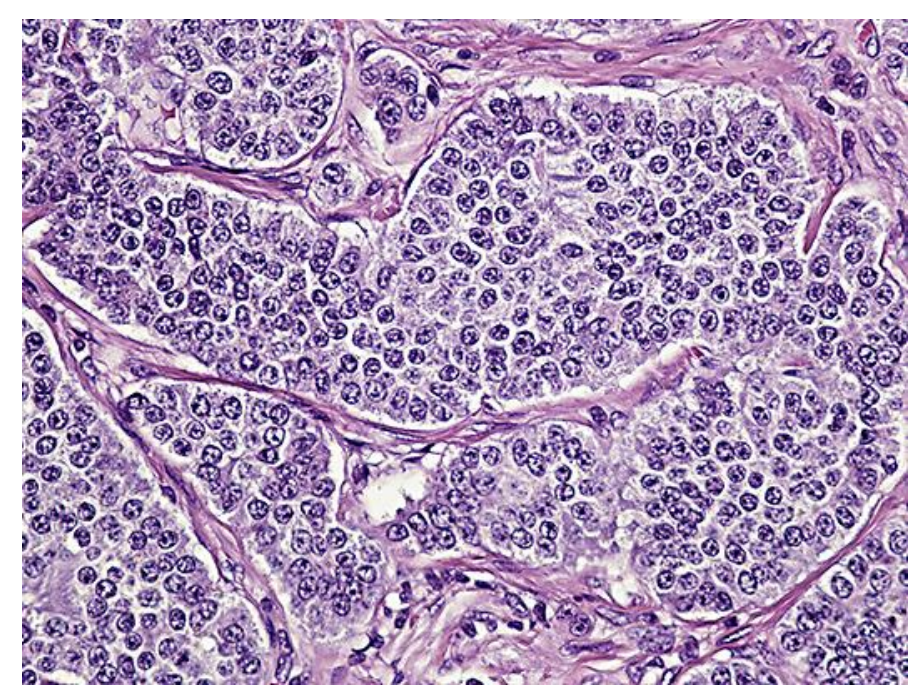

Fig. 2. The tumor cells are arranged in nests and trabecular pattern and composed of small uniform cells with centrally located round nuclei and dispersed chromatin. Delicate vessels are present within the tumor stromal tissue. H\&E stain. $\times 100$ magnification. 


\section{Case Reports in \\ Gastroenterology \\ Case Rep Gastroenterol 2016;10:793-799

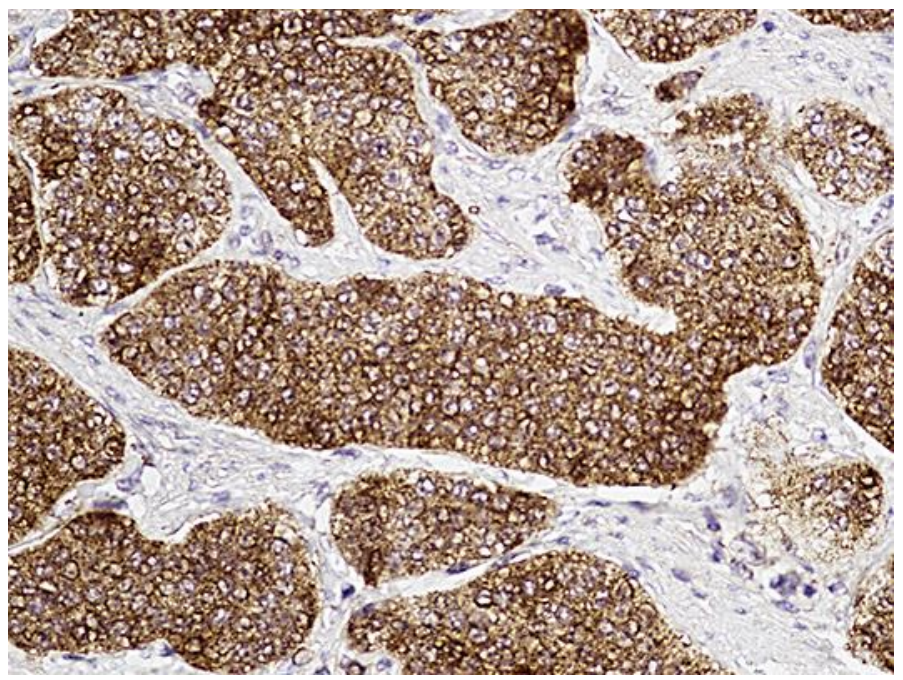

Fig. 3. The endocrine differentiation of this tumor is highlighted by strong cytoplasmic positivity to neuronspecific enolase. Immunohistochemistry. $\times 100$ magnification.

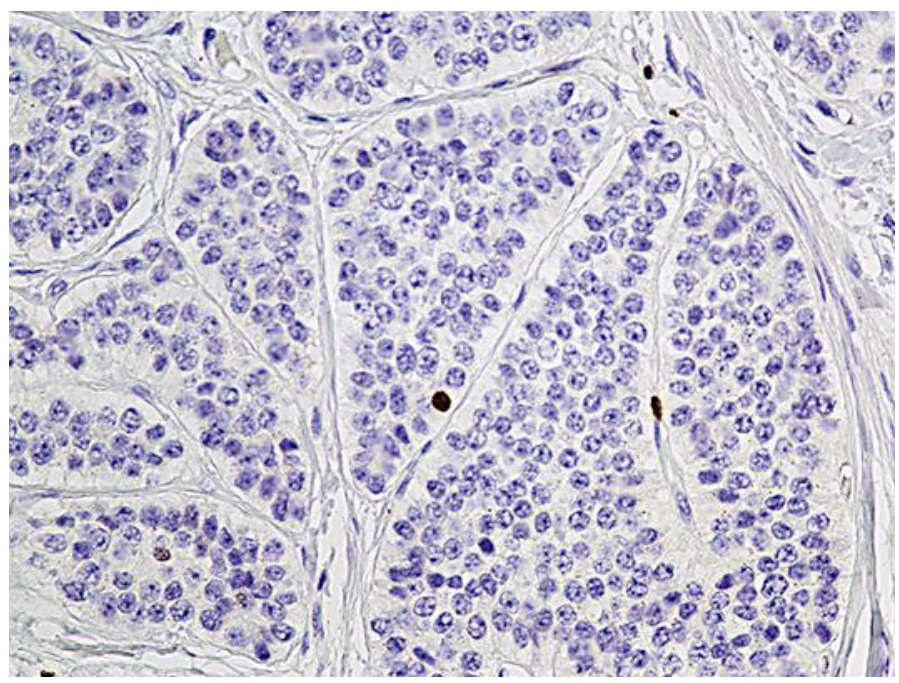

Fig. 4. Ki-67 immunostaining shows the tumor cells have a low proliferative rate $<2 \%$. 